\title{
Observations on the Influence of Precursor Conformations on Macrocyclization Reactions
}

\author{
Hammershøj, Peter; Beldring, Klavs; Nielsen, Anders R.; Fristrup, Peter; Clausen, Mads Hartvig
}

Published in:

European Journal of Organic Chemistry

Link to article, DOI:

10.1002/ejoc.201501445

Publication date:

2016

Document Version

Peer reviewed version

Link back to DTU Orbit

Citation (APA):

Hammershøj, P., Beldring, K., Nielsen, A. R., Fristrup, P., \& Clausen, M. H. (2016). Observations on the Influence of Precursor Conformations on Macrocyclization Reactions. European Journal of Organic Chemistry, 2016(8), 1533-1540. https://doi.org/10.1002/ejoc.201501445

\section{General rights}

Copyright and moral rights for the publications made accessible in the public portal are retained by the authors and/or other copyright owners and it is a condition of accessing publications that users recognise and abide by the legal requirements associated with these rights.

- Users may download and print one copy of any publication from the public portal for the purpose of private study or research.

- You may not further distribute the material or use it for any profit-making activity or commercial gain

- You may freely distribute the URL identifying the publication in the public portal 
 \\ Observations on the Influence of Precursor Conformations on Macrocyclization Reactions
}

\author{
Peter Hammershøj, ${ }^{[a],[b]}$ Klavs Beldring, ${ }^{[a],[b]}$ Anders R. Nielsen, ${ }^{[a],[b]}$ Peter Fristrup, ${ }^{*}{ }^{[b]}$ Mads H. \\ Clausen. ${ }^{*[a],[b]}$
}

\begin{abstract}
Macrocycles hold great promise in drug discovery as an underutilized class of lead compounds. The low abundance of these molecules can in part be explained by the inherent difficulties in the synthesis of macrocycles and the lack of general methods for their rapid assembly. We have undertaken a research program aimed at developing methods for facile synthesis of macrocycles from simple precursors. The synthesis of two new cyclization precursors is described and the results of their reaction with thionyl chloride are presented and discussed. Where one acyclic diol, smoothly underwent macrocyclization to afford a mixture of diastereomeric sulfites, subjection of the other precursor to identical reaction conditions resulted in the isolation of the linear dichloride. We hypothesize that there is a difference in the ability of the two molecules to adopt a conformation germane to macrocyclization, a proposition that is supported by conformational analyses using molecular mechanics.
\end{abstract}

\section{Introduction}

Macrocycles are an underutilized class of molecules in drug discovery, ${ }^{1,2,3}$ despite their unique ability to address difficult targets, ${ }^{4}$ such as protein-protein interactions, a fact that can be attributed to the inherent difficulty in preparing large rings. ${ }^{5}$ Macrocyclic peptides and peptidomimetics are a sub-class of macrocycles, the synthesis ${ }^{6}$ and easy of cyclization ${ }^{7,8}$ of which have been topics of excellent recent papers. The macrocyclization chemistry of particular challenging cyclophane natural products has similarly been highlighted ${ }^{9}$ and the efficiency of such reactions in terms of the relation between chemical yield and concentration was also addressed lately. ${ }^{10}$ In order to harvest the potential of macrocycles for screening campaigns, one has to face the challenges posed by this compound class: the chemistry of cyclization is also the chemistry of oligomerization, which often compels that high dilution conditions are employed. Furthermore, macrocyclization reactions are known to be sensitive to conformational effects, ${ }^{11}$ something that is studied employing computational methods in this manuscript. Indeed, the importance of configurational, conformational, and template-induced preorganization in macrocyclization reactions has been the topic of a number of recent reports and was reviewed in 2015 by Luis and coworkers. ${ }^{12}$

In recent years, several groups have contributed towards rationalizing the success or failure of macrocyclizations of large rings. ${ }^{12}$ The success of using simple force-field based modeling on the conformations of small and medium-sized rings was achieved already in the early and mid-1980s by Still and coworkers $^{13}$ and molecular mechanics calculations have been applied to predict the most productive precursors of cyclic peptides. ${ }^{14}$ More recently, conformational and configurational pre-organization in macrocyclization has been studied, e.g. folding of oligoamides, ${ }^{15}$ synthesis of cycloparaphenylens, ${ }^{16}$ and peptidomimetic macrocycles. ${ }^{17}$

In order to address the dearth of novel macrocyclic scaffolds for screening campaigns, we have undertaken a research program aimed at developing methods for facile synthesis of macrocycles from simple precursors. ${ }^{18,19}$ In the course of these investigations, we have produced acyclic diols and tested their propensity to undergo macrocyclization, choosing the formation of sulfites as a representative reaction. Examples of successful cyclizations of this type are shown in Scheme 1: diol 1 cyclized in impressive $79 \%$ yield to sulfite 2 using our standard conditions (dropwise addition of thionyl chloride to a $10 \mathrm{mM}$ solution of diol in methylene chloride, triethylamine, DMAP). ${ }^{19}$ Similarly, the ester 3 formed from 6-hydroxycaproic acid cyclized to form 5 in 55\% yield - but a similar ester from a sorbic acid derivative (4) was considerably less willing to form the cyclic sulfite, which could be obtained in just $25 \%$ yield. ${ }^{18}$
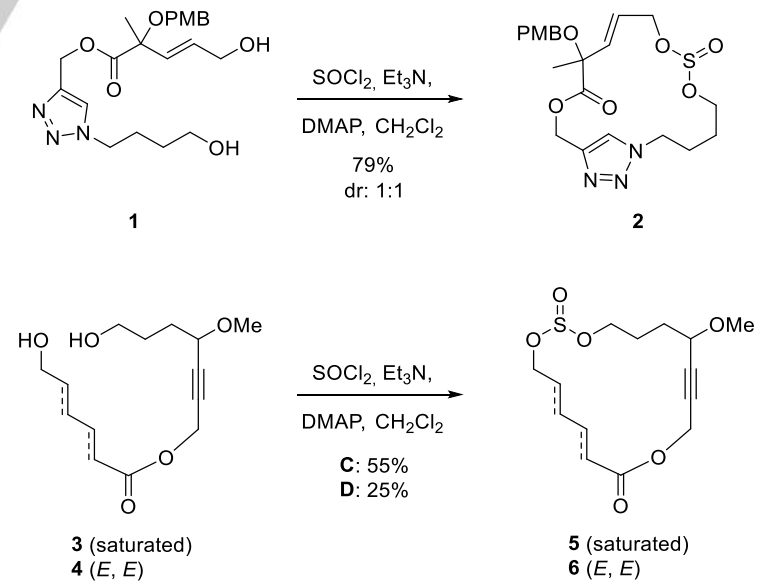

Scheme 1. Previously synthesized macrocyclic sulfites $(2,5$ and 6) and the variation in yields for different acyclic diols (1, 3 and

[a] Center for Nanomedicine and Theranostics Technical University of Denmark Building 207, DK-2800 Kgs. Lyngby, Denmark

[b] Department of Chemistry Technical University of Denmark Building 207, DK-2800 Kgs. Lyngby, Denmark, 
4).

In order to unlock the potential of macrocyclic scaffolds in lead discovery it is important to have general conditions for cyclization reactions, which is why we became interested in studying the cyclization of different precursors. Furthermore, we were looking for trends regarding the pre-cyclization conformations that could potentially predict the propensity to macrocyclize efficiently. In this report, we discuss the synthesis of two precursors that show very different reactivity in the formation of cyclic sulfites as a model reaction and disclose the results of molecular mechanics simulations of their conformations.

\section{Results and Discussion}

Synthesis. In order to study the synthesis of different macrocycles the two novel building blocks 11 and 21 were synthesized (Scheme 2).

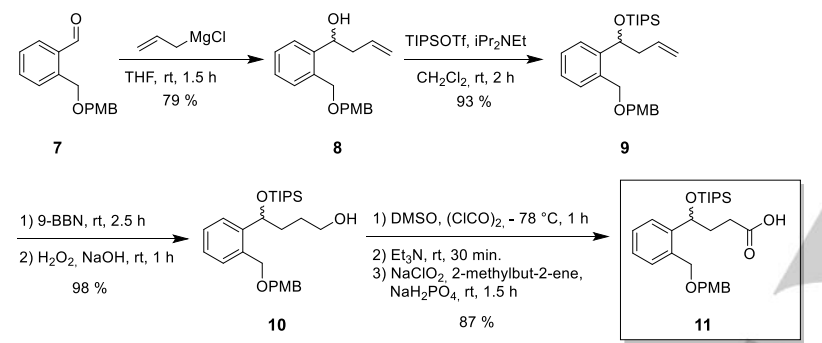

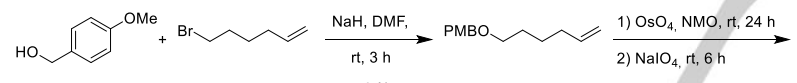

$$
\begin{aligned}
& 12 \\
& 13 \\
& 56 \% \\
& 14
\end{aligned}
$$

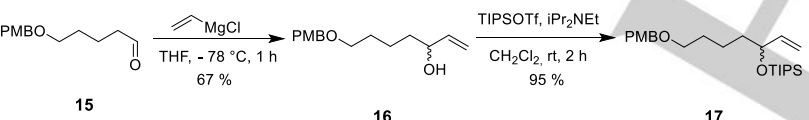
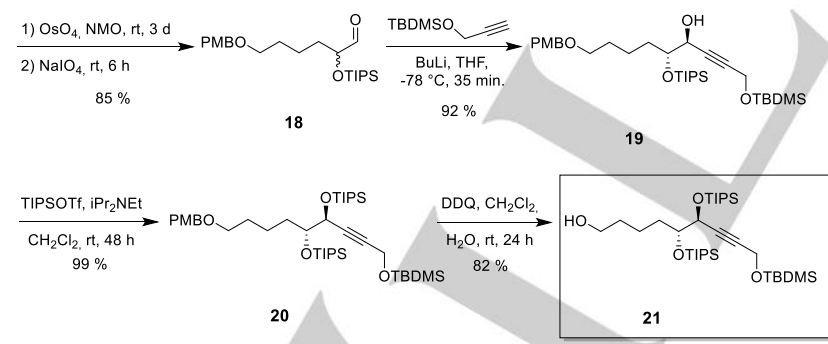

Scheme 2. Synthetic route to building blocks 11 and 21.

\section{A Grignard reaction with} methoxybenzyl)oxy)methyl)benzaldehyde chloride afforded the racemic mixture of $\mathbf{8}^{20,2}$ Protection of the hydroxyl group was achieved using TIPSOTf and compound 9 could be transformed to the corresponding alcohol 10 by an anti-Markovnikov-addition ${ }^{22}$ of a hydroxyl group to the alkene by addition of 9-BBN followed by hydrogen peroxide. $^{23}$ Thus, the newly formed alcohol $\mathbf{1 0}$ was first subjected to the Swern oxidation conditions ${ }^{24}$ to afford the corresponding crude aldehyde followed by oxidation to acid 11 using $\mathrm{NaClO}_{2}, \mathrm{NaH}_{2} \mathrm{PO}_{4}$, and 2-methylbut-2-ene ${ }^{25}$ in $87 \%$ yield. The synthetic route to compound 21 started with treatment of commercially available (4-methoxyphenyl)methanol (12) and 6bromohex-1-ene (13) with $\mathrm{NaH}$ in DMF. After protection of the hydroxyl group with PMB, compound 14 was transformed to aldehyde 15 by a one-pot reaction via the diol by treatment first with $\mathrm{OsO}_{4} / \mathrm{NMO}^{26}$ followed by cleavage of the diol with $\mathrm{NaIO}_{4}{ }^{27} \mathrm{~A}$ Grignard reaction using vinylmagnesium bromide in THF at $-78{ }^{\circ} \mathrm{C}$ afforded the racemic mixture of alcohol $16 .{ }^{20}$ After protection of the hydroxyl group with TIPS to afford compound 17, the alkene group was once more transformed following the same procedure as mentioned for $14 \rightarrow 15$, yielding aldehyde 18. Introduction of an alkyne moiety was achieved using the commercially available tertbutyldimethyl(prop-2-yn-1-yloxy)silane and BuLi in THF at $78{ }^{\circ} \mathrm{C}$ forming the reactive alkynelithium reagent. The addition to give 19 afforded a single diastereoisomer in $92 \%$ yield, which was shown to be the Felkin product ${ }^{28}$ by treatment of 19 with aqueous $\mathrm{HCl}$ in acetone, deprotecting the silyl ethers and generating the acetonide of the vicinal diols. The product was analyzed by NMR and a NOESY spectrum confirmed the cis orientation of the protons in the five-membered acetonide. Alcohol 19 was protected with TIPS to give compound 20, which was then treated with $\mathrm{DDQ}^{29}$ to remove the $\mathrm{PMB}$ group and provide 21 , obtained in an overall yield of $16 \%$ over 8 steps.
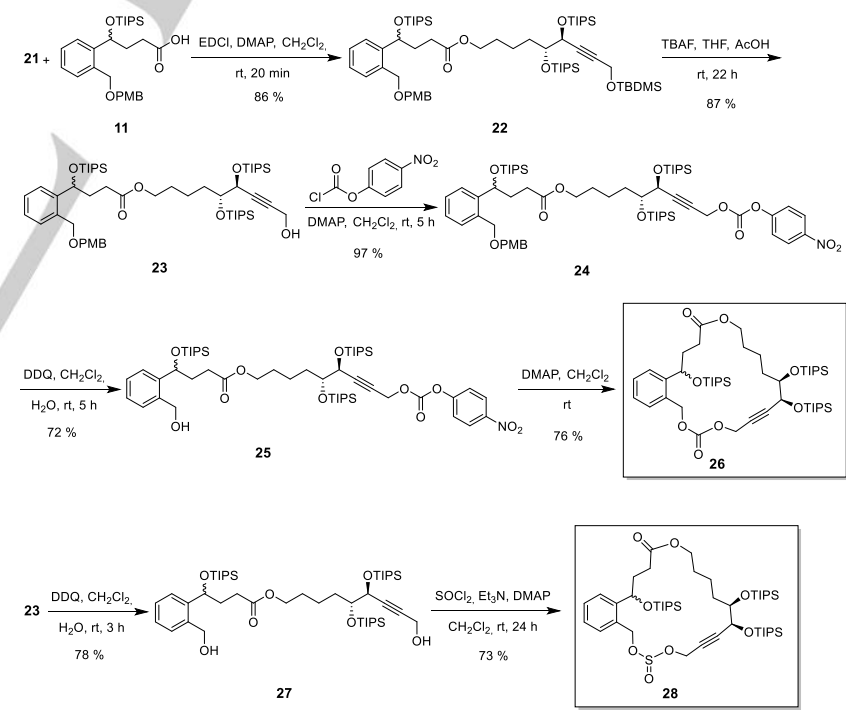

Scheme 3. Synthetic route to macrocyclic carbonate 26 and sulfite 28 from compounds 11 and 21 .

The two exemplary macrocyclic target molecules were carbonate $\mathbf{2 6}$ and sulfite $\mathbf{2 8}$ (Scheme 3). Starting from $\mathbf{1 1}$ and $\mathbf{2 1}$, the diastereomeric mixture of compound 22 was generated using equivalent amount of DMAP and an excess of EDCl. Next, the primary alcohols in compound $\mathbf{2 2}$ needed to be deprotected. Treatment with TBAF under mild conditions in $\mathrm{AcOH} / \mathrm{THF}$ gave selective deprotection of the TBDMS protected hydroxyl group 
yielding alcohol 23. The first part of the synthetic route towards the target macrocyclic carbonate $\mathbf{2 6}$ was started with alcohol $\mathbf{2 3}$, which was reacted with $p$-nitrophenylchloroformate and DMAP to form carbonate intermediate $\mathbf{2 4}$ in high yield. Before the first cyclization attempt, the other primary alcohol was unmasked by treatment with DDQ. Base catalyzed intramolecular cyclization of primary alcohol $\mathbf{2 5}$ yielded macrocyclic carbonate $\mathbf{2 6}$ in $\mathbf{7 6 \%}$ yield (40\% overall yield starting from 11 and 21). The second part of the synthetic route leads to sulfite $\mathbf{2 8}$ utilizing the same key intermediate compound 23. Before cyclization to the sulfite, the second primary alcohol in compound $\mathbf{2 3}$ was deprotected with the same procedure as mentioned for $\mathbf{2 4} \rightarrow \mathbf{2 5}$. Thus, treatment of the isolated diol $\mathbf{2 7}$ with an excess of thionyl chloride and triethylamine with a catalytic amount of DMAP yielded macrocyclic sulfite 28 in an overall yield of $43 \%$ from building blocks 11 and 21 .
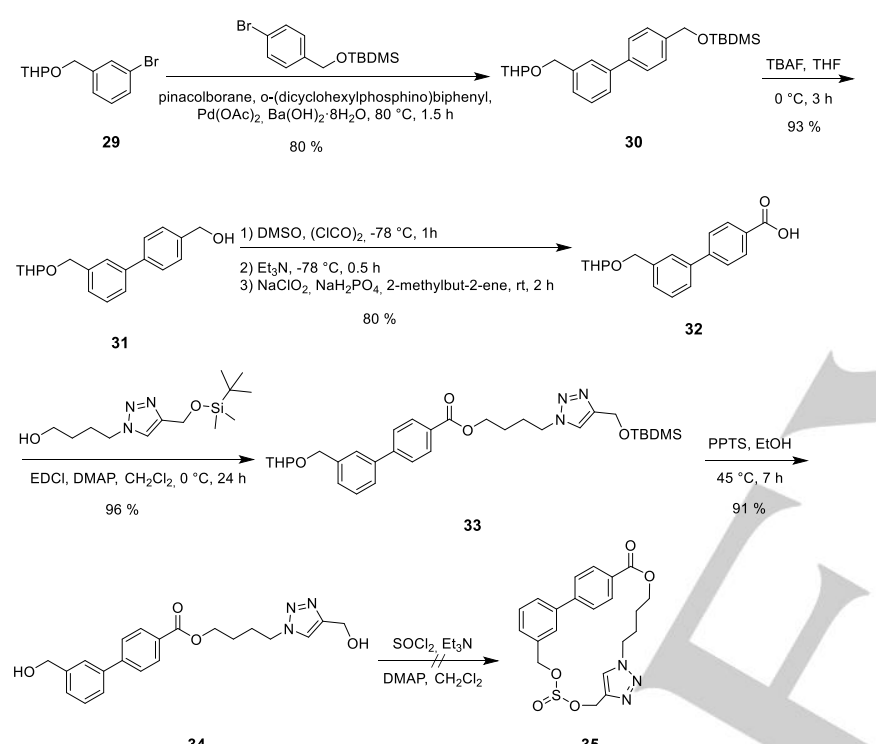

Scheme 4. Synthetic route to diol $\mathbf{3 4}$ and attempt to produce macrocyclic sulfite 35 .

The second synthetic route towards macrocyclic target molecules sulfite $\mathbf{3 5}$ was chosen to introduce a rigid biphenyl motif into the macrocycle structure, the route is shown in Scheme 4. The synthesis started with a one-pot boronationSuzuki cross-coupling reaction initiated by in situ formation of the alkylborate of 2-((3-bromobenzyl)oxy)tetrahydro-2H-pyran (29) followed by addition of 4-bromobenzyloxy)(tertbutyl)dimethylsilane along with $\mathrm{Pd}(\mathrm{OAc})_{2}$, and $\mathrm{Ba}(\mathrm{OH})_{2} \cdot 8 \mathrm{H}_{2} \mathrm{O}$ affording biphenyl $30{ }^{30}$ Selective deprotection of the TBDMS protected hydroxyl group was achieved using TBAF in THF in close to quantitative yield. Thus, the newly formed alcohol $\mathbf{3 1}$ was first subjected to the Swern oxidation conditions to afford the corresponding crude aldehyde followed by oxidation to acid 32 using $\mathrm{NaClO}_{2}, \quad \mathrm{NaH}_{2} \mathrm{PO}_{4}, \quad$ and 2-methylbut-2-ene. Esterification of acid 32 with 4-(4-(( tertbutyldimethylsilyl)oxy)methyl)-1H-1,2,3-triazol-1-yl)butan-1olError! Bookmark not defined. was achieved with EDCl and
DMAP in DCM at $5{ }^{\circ} \mathrm{C}$ affording ester 33 . Before the first attempt to cyclize to sulfite 35 , the two hydroxyl groups had to be deprotected and this was achieved by treatment of ester $\mathbf{3 3}$ with PPTS in EtOH affording the key intermediate diol 34. Under the same reaction condition as for the cyclization reaction $\mathbf{2 7} \rightarrow \mathbf{2 8}$ diol 34 did not undergo cyclization, affording instead a dichlorinated product (S17, see supporting information).

\section{Molecular modeling.}

With the rapid development of computational capability in the last two decades in mind we speculated that it might indeed be possible to generate a large number of possible conformations for the large and flexible cyclization precursors studied here. With the experimental data for the successful macrocyclizations of diol precursors 1, 3 and 4 available we carried out a simple conformational search using the OPLS-2005 force-field ${ }^{31}$ and a GB/SA solvation model ${ }^{32}$ for water as incorporated in Macromodel version 9.6. ${ }^{33}$ The conformational search was carried out using a combination of the Monte Carlo multiple minimum (MCMM) algorithm ${ }^{34,35}$ and the Low-Mode search algoritm. ${ }^{36}$ We found conformations with a hydrogen bond established between the two terminal $\mathrm{OH}$ as the global minimum for all three compounds indicating that macrocyclization is not prohibited by strain (structures and energies included in supporting information).

While this was a very satisfactory and interesting first result, we were interested in constructing a computational approach, which could guide our synthesis efforts. We speculated that a long conformational search (10000 steps) with a large energy window of $100 \mathrm{~kJ} \mathrm{~mol}^{-1}$ would allow generation of representative conformational ensemble (typically 5-7,000 structures). From this ensemble we could then compare both the number and the relative energy of the conformations amendable to cyclization (i.e. short end-to-end distance) in comparison with the data gathered from the entire ensemble (energy vs. end-to-end distance). Ultimately, our goal is to be able to use such a conformational search as a first, rough indication of whether or not the chosen backbone is suitable for synthesis.

Application of this extended conformational search confirmed the existence of a stabilizing hydrogen bond and this conformation was found to be the global minimum for all three compounds (1, $\mathbf{3}$ and 4). We carried out the same conformational search for the two possible intermediates where one of the alcohols had reacted with $\mathrm{SO}_{2} \mathrm{Cl}_{2}$ to form a SOClmoeity. This analysis was carried out for all six possible intermediates formed from diols $\mathbf{1}, \mathbf{3}$ and $\mathbf{4}$, and while the global minimum did not always have a short end-to-end distance there were always conformations with energies only a few $\mathrm{kJ} / \mathrm{mol}$ higher than the global minimum that did (see supporting information for details).

In this first study, we apply the methodology to two series of cyclization precursors, one which undergoes smooth macrocyclization and one which does not cyclize. While it is obviously advantageous to limit the computational investigation 
to the cyclization precursors (diols in this study) we also include the two possible intermediates where the cyclization reagent $\left(\mathrm{SOCl}_{2}\right)$ has reacted with one of the two possible termini as has been done for the previously studied molecules 1, 3 and $\mathbf{4}$.

The cyclization precursor, in this case both of the stereoisomers of diol 27, was built and subjected to a conformational search for 10,000 steps. As both stereoisomers gave very similar results we only include the results from the (R)-enantiomer here. In total, 7,052 conformations were generated and the relative energy plotted as function of the $\mathrm{O}-\mathrm{O}$ distance of the two free alcohols (Figure 1A).

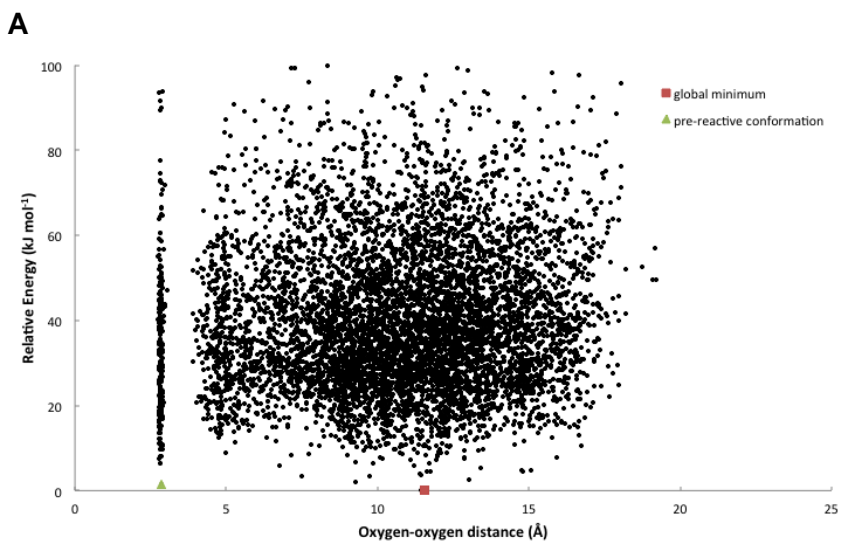

B

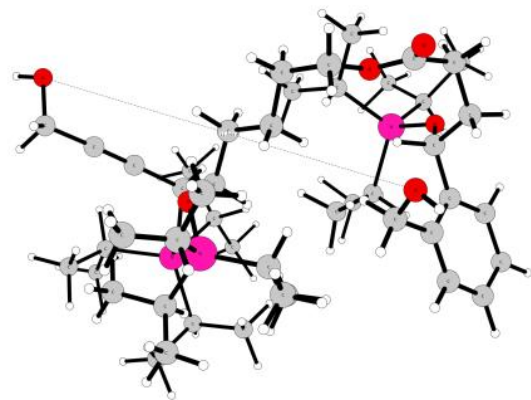

C

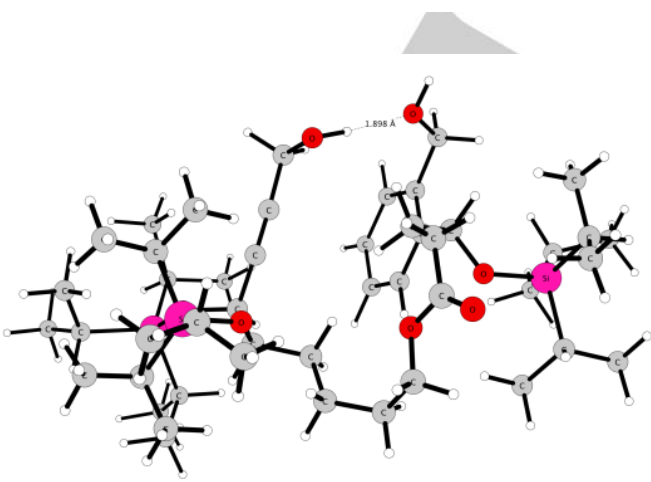

Figure 1. A) Results from the conformational search of compound 27. B) Global minimum obtained in the conformational search of compound 27. C) Conformation no. 3 with a relative energy of $1.5 \mathrm{~kJ} \mathrm{~mol}^{-1}$ and a hydrogen bond between the two alcohols. Images were constructed using XYZviewer. ${ }^{37}$

While the global minimum was characterized by having a rather long distance between the two free alcohols $(11.5 \AA$, Figure $1 \mathrm{~A}$, red dot and Figure $1 B)$, the conformation with $3^{\text {rd }}$ lowest energy had a very short oxygen-oxygen distance (1.9 $\AA$, Figure $1 \mathrm{~A}$ green dot and Figure $1 \mathrm{C}$ ). This clearly shows that a structure which is pre-organized for cyclization is indeed energetically accessible at room temperature, thus providing theoretical support for the high yield obtained in the cyclization reaction. A simple two-state Boltzmann expression shows that an energy difference of $1.5 \mathrm{~kJ} \mathrm{~mol}^{-1}$ corresponds to approximately $35 \%$ population at room temperature. The oxygen-oxygen distance of ca. $1.8 \AA$ is shorter than the oxygen-oxygen distance in the final,

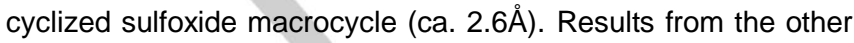
stereoisomer were similar except for the fact that here even the global minimum had a conformation with short oxygen-oxygen distance (both stereoisomers are included in the supporting information)

For compound $\mathbf{3 4}$ a similar conformational search was carried out which resulted in 5,190 structures, where the global minimum had an O-O distance of $7.8 \AA$ (Figure $3 \mathrm{~A}$ and $3 \mathrm{~B}$ ). Here none of the most energetically favored structures had a similar short $\mathrm{O}-\mathrm{O}$ distance, and only two structures could be found in total. These two had O-O distances of $2.9 \AA$ and relative energies of 7.4 (Figure $3 \mathrm{C}$ ) and $13.8 \mathrm{~kJ} \mathrm{~mol}^{-1}$ compared to the global minimum, respectively. A simple two-state Boltzmann expression shows that an energy difference of $7.4 \mathrm{~kJ}$ $\mathrm{mol}^{-1}$ corresponds to approximately $5 \%$ population at room temperature. However, juding by the graph it is clear that there are many more low-energy conformations with long $\mathrm{O}-\mathrm{O}$ distances so the real population of conformations with short $\mathrm{O}-\mathrm{O}$ distances will be much lower.

A

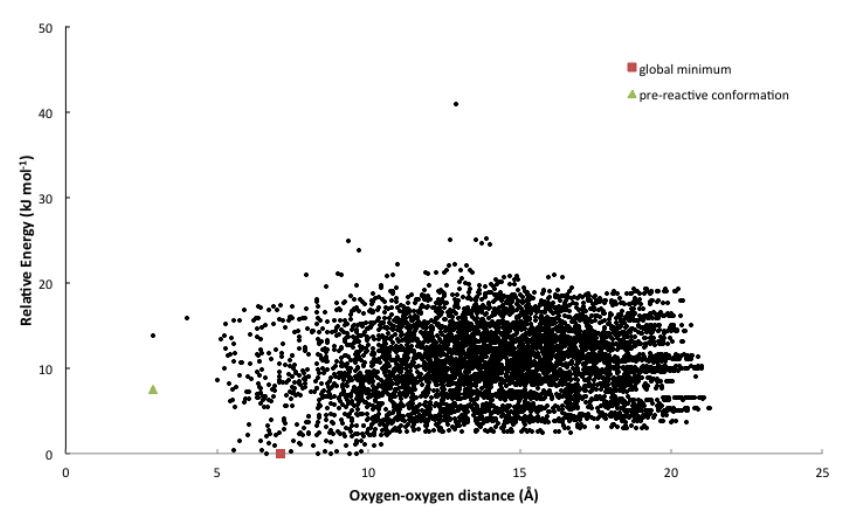

B 


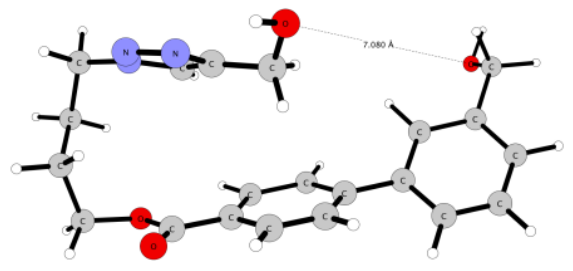

C

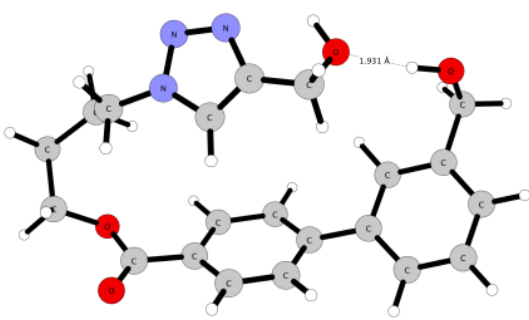

previously. Here, 1 cyclized in impressive $79 \%$ yield to sulfite 2 . Similarly, the ester $\mathbf{3}$ formed from 6-hydroxycaproic acid cyclized to form 5 in $55 \%$ yield - but a similar ester from a sorbic acid derivative (4) was considerably less willing to form the cyclic sulfite, which could be obtained in only $25 \%$ yield.

The conformational search was carried out on the pre-cursor 1, which resulted in 7,379 conformations. Of these conformations, 92 were pre-organized for cyclization in that they had a hydrogen bond between the two termini, which was confirmed by a short oxygen-oxygen distance $(<3 \AA)$. Conformation no. 46 was the most favorable of these and it had a relative energy of $3.5 \mathrm{~kJ} \mathrm{~mol}^{-1}$ compared to the global minimum (Figure S1, supporting information). This is in line with the observed ease of cyclization and excellent yield.

A

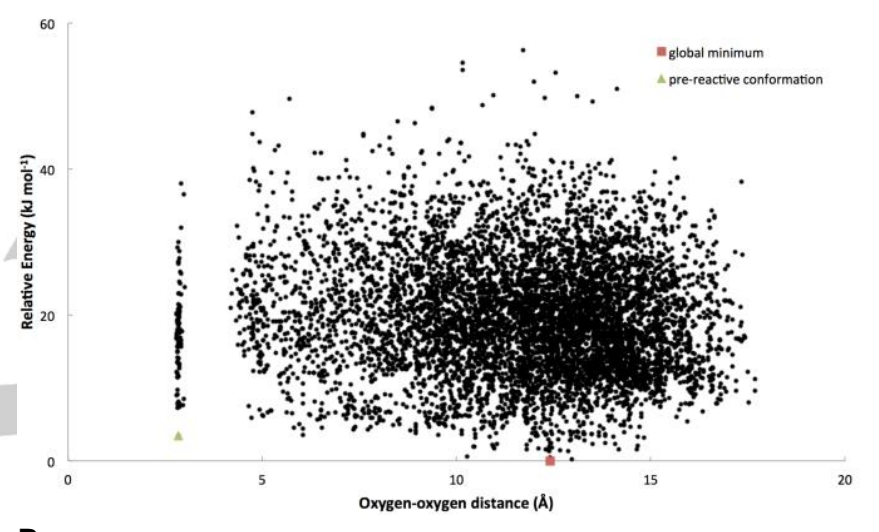

B

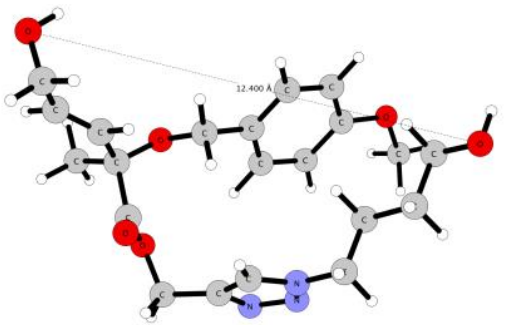

compound 279 conformations with short O-O distances $\left(<3 \AA\right.$ ) exists that are within $10 \mathrm{~kJ} \mathrm{~mol}^{-1}$ of the global minimum. Furthermore, for compound $\mathbf{2 7}$ we found a total of 249 structures with a very short $\mathrm{O}-\mathrm{O}$ distance $(<3 \AA)$ indicative of a possibility for a productive ring closing reaction. For compound $\mathbf{3 4}$ only 2 conformations that satisfy the constraint of having a short $\mathrm{O}-\mathrm{O}$ distance within the entire ensemble of ca. 5,000 structures generated during the conformational search. Given that the precursors $\mathbf{2 7}$ and $\mathbf{3 4}$ have the same functional groups with similar reactivities (benzylic and propargylic alcohols for 27, benzylic and heterobenzylic for 34 ), were reacted under identical conditions and were converted to different products, it seems plausible that the major reason why 27 underwent cyclization and 34 was instead chlorinated is the ease with which the precursors can adopt a conformation germane to cyclization.

With this computational methodology in hand we also went back and analyzed the cyclizations of precursors $\mathbf{1}, \mathbf{3}$, and 4 reported

\section{C}

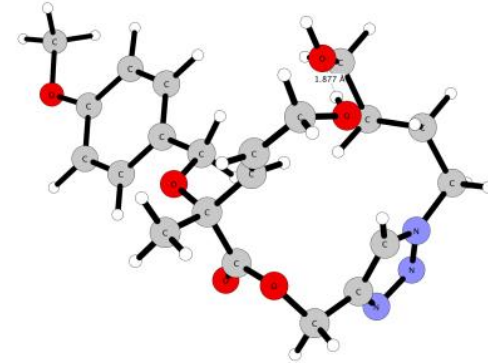


Figure 3. A) Results from the conformational search of 1. B) Global minimum obtained in the conformational search of compound 1. C) Conformation no. 46 from the conformational search of $\mathbf{1}$ which has a relative energy of $3.5 \mathrm{~kJ} \mathrm{~mol}^{-1}$ and a hydrogen bond between the two alcohols.

For compound 3 (saturated) and 4 (unsaturated) a similar approach was taken which resulted in 7,996 and 6,787 conformations, respectively (Figure S4, supporting information). For both of these structures the global minimum displayed a conformation prone to cyclization stabilized by a hydrogen bond interaction between the two alcohols (Figure S7, supporting information). When we analyze the number of conformations that have a sufficiently short oxygen-oxygen distance $(<3.0 \AA)$ we find 250 conformations for 3 compared to 121 conformations for 4 . The higher number of pre-reactive conformations found for 3 provides a possible explanation for the observed higher yield in the macrocyclization of $\mathbf{3}$ compared to $\mathbf{4}$.

Although the analysis performed here is rudimentary and does not for example involve a detailed analysis of the transition state for the cyclization reaction, it does have the benefit of being extremely fast and simple to perform. We recommend that all programs aimed at generating macrocyclic products, especially in a parallel synthesis setting, include a simple analysis of cyclization precursors similar to the one outlined here. An upfront investigation of the degrees of freedom involved, the number of conformations amendable to cyclization and their relative energies can give a good indication as to whether a given precursor should be included in a library design.

\section{Conclusions}

We have presented the synthesis of two diol precursors for cyclization to form e.g. sulfites. The alcohol groups have comparable reactivity based on their stereoelectronic properties and still one was shown to afford a cyclic sulfite smoothly, while the other precursor exclusively gave an acyclic dichloride under identical conditions. The propensity of the precursors to adopt a conformation that was deemed fit for a productive cyclization was examined through a long conformational search (10000 steps) that was carried out with a large energy window of $100 \mathrm{~kJ}$ $\mathrm{mol}^{-1}$ to allow generation of representative conformational ensemble (typically 5-7,000 structures).

The proportion of conformations with a short end-to-end distance was compared and was shown to be in line with the observed experimental results. In addition, the conformational space of the two possible intermediates where one of the alcohol had reacted with $\mathrm{SOCl}_{2}$ was investigated. Interestingly, we found that this change did not result in major differences in the overall distribution of conformers. Our observations underline the importance of conformational analysis for macrocyclization reactions and offer a facile modeling method for performing a first examination of conformational space of cyclization precursors.

\section{Experimental Section}

General experimental procedure for the formation of macrocyclic sulfite 28 and dichloride 35 . The diol cyclization precursor $(0.14 \mathrm{mmol})$ was dissolved in anhydrous $\mathrm{CH}_{2} \mathrm{Cl}_{2}(14 \mathrm{~mL})$ and DMAP (9 $\mathrm{mg}, 0.07 \mathrm{mmol}$ ) and $\mathrm{Et}_{3} \mathrm{~N}(0.05 \mathrm{~mL}, 0.42 \mathrm{mmol})$ were added under a nitrogen atmosphere. The reaction mixture were stirred and $\mathrm{SOCl}_{2}(11 \mu \mathrm{L}, 0.16 \mathrm{mmol})$ dissolved in anhydrous $\mathrm{CH}_{2} \mathrm{Cl}_{2}(3 \mathrm{~mL})$ was added drop wise over a period of $10 \mathrm{~min}$ at room temperature. After 2 hours an additional amount of $\mathrm{SOCl}_{2}(6 \mu \mathrm{L}, 0.08 \mathrm{mmol})$ dissolved in anhydrous $\mathrm{CH}_{2} \mathrm{Cl}_{2}(1 \mathrm{~mL})$ were added. After 18 hours $\mathrm{Et}_{3} \mathrm{~N}(16 \mu \mathrm{L}, 0.14 \mathrm{mmol})$ and $\mathrm{SOCl}_{2}(6 \mu \mathrm{L}, 0.08$ mmol) dissolved in anhydrous $\mathrm{CH}_{2} \mathrm{Cl}_{2}(1 \mathrm{~mL})$ were added and the reaction mixture were stirred for an additional 2 hours. After full conversion (evaluated by TLC) the reaction mixture were evaporated to dryness in vacuo. The residue was purified by column chromatography (heptane/EtOAc) on silica gel to give the pure product.

Keywords: Macrocycles • synthesis • molecular modelling • conformational analysis

[1] C. M. Madsen, M. H. Clausen, Eur. J. Org. Chem. 2011, 31073115.

[2] E. M. Driggers, S. P. Hale, J. Lee, N. K. Terrett, Nat. Rev. Drug Disc. 2008, 7, 608-624.

[3] E. Marsault, M. L. Peterson, J. Med. Chem. 2011, 54, 1961-2004.

[4] W. Brandt, V. J. Haupt, L. A. Wessjohann Curr. Top. Med. Chem. 2010, 10, 1361-1379.

[5] L. A. Wessjohann, E. Ruijter, D. Garcia-Rivera, W. Brandt, Mol. Diversity 2005, 9, 171-186.

[6] C. J. White, A.K. Yudin, Nature Chem. 2011, 3, 509-524.

[7] A. Thakkar, T. B. Trinh, D. Pei, ACS Comb. Sci. 2013, 15 120-129.

[8] J. Becerril, M. Bolte, M. I. Burguete, F. Galindo, E. GarcíaEspaña, S. V. Luis, J. F. Miravet, J. Am. Chem. Soc. 2003, 125, 6677-6686.

[9] T. Gulder, P. S. Baran, Nat. Prod. Rep. 2012, 29, 899-934.

[10] J. C. Collins, K. James, Med. Chem. Commun. 2012, 3, 14891495.

[11] J. Blankenstein, J. Zhu, Eur. J. Org. Chem. 2005, 1949-1964. V. Martí-Centelles, M. D. Pandey, M. I. Burguete, S. V. Luis, Chem. Rev. 2015, 115, 8736-8834.

[12] V. Martí-Centelles, M. D. Pandey, M. I. Burguete, S. V. Luis, Chem. Rev. 2015, 115, 8736-8834.

[13] a) W. C. Still, I. Galynker, Tetrahedron 1981, 37, 3981-3996. b) W. C. Still, I. Galynker, J. Am. Chem. Soc. 1982, 104, 1774-1776.

[14] F. Cavelier-Frontin, G. Pepe, J. Verducci, D. Siri, R. Jacquier, J. Am. Chem. Soc. 1992, 114, 8885-8890.

[15] L. H. Yuan, H. Q. Zeng, K. Yamato, A. R. Sanford, W. Feng, H. Atreya, D. K. Sukumaran, T. Szyperski, B. Gong, J. Am. Chem. Soc. 2004, 126, 16528-16537.

[16] Y. Segawa, S. Miyamoto, H. Omachi, S. Matsuura, P. Senel, T. Sasamori, N. Tokitoh, K. Itami, Angew. Chem., Int. Ed. 2011, 50, 3244-3248. 
[17] M. Bru, I. Alfonso, M. I. Burguete, W. V. Luis, Tetrahedron Lett. 2005, 46, 7781-7785.

[18] M.J. Wingstrand, C.M. Madsen, M.H. Clausen, Tetrahedron Lett. 2009, 50, 693-695.

[19] C.M. Madsen, M. Hansen, M.V. Thrane, M.H Clausen, Tetrahedron 2010, 66, 9849-9859.

[20] a) V. Grignard, C. R. Acad. Sci. 1900, 1322.1324. b) V. Grignard Ann. Chim. 1901, 7, 433-490.

[21] M. Jay-Smith, D. P. Furkert, J. Sperry, M. A. Brimble, Synlett 2011, 1395-1398.

[22] W. Markownikoff. Ann. Chim. 1870, 228-259.

[23] a) R. Liotta, H. C. Brown, Hydroboration. 48. J. Org. Chem. 1977, 42, 2836-2839. b) H. C. Brown, J. V. N. V. Prasad, J. Org. Chem. 1985, 50, 3002-3005.

[24] D. Swern, A. J. Mancuso, Synthesis 1981, 165-185.

[25] B. O. Lindgren, T. Nilsson, Acta Chem. Scand. 1973, 27, 888-890.

[26] V. VanRheenen, R. C. Kelly, D. Y. Cha, Tetrahedron Lett. 1976, 17, 1973-1976.

[27] B. Sklarz, Q. Rev. Chem. Soc. 1967, 21, 3-28.

[28] M. Chérest, H. Felkin, N. Prudent, Tetrahedron Lett. 1968, 9, 2199-2204.

[29] Y. Oikawa, T. Yoshioka, O. Yonemitsu, Tetrahedron Lett. 1982 23, 885-888.

[30] a) N. Miyaura, A. Suzuki, J. Chem. Soc., Chem. Commun. 1979 866-867. b) N. Miyaura, K. Yamada, A. Suzuki, Tetrahedron Lett. 1979, 3437-3440.

[31] G. A. Kaminski, R. A. Friesner, J. Tirado-Rives, W. J. Jorgensen, J. Phys. Chem. B 2001, 105, 6474-6487.

[32] W. C. Still, A. Tempczyk, R. C. Hawley, T. Hendrickson, J. Am. Chem. Soc. 1990, 112, 6127-6129.

[33] MacroModel v. 9.9 from Schrödinger Inc.: F. Mohamadi, N. G. J Richards, W. C. Guida, R. Liskamp, M. Lipton, C. Caulfield, G. Chang, T. Hendrickson, W. C. Still, J. Comput. Chem. 1990, 11, 440-467. For current versions, see: http://www.schrodinger.com

[34] G. Chang, W. C. Guida, W. C. Still, J. Am. Chem. Soc. 1989, 111, 4379-4386.

[35] M. Saunders, K. N. Houk, Y.-D. Wu, C. W. Still, M. Lipton, G. Chang, W. C. Guida, J. Am. Chem. Soc. 1990, 112, 1419-1427.

[36] I. Kolossváry, W. C. Guida, J. Am. Chem. Soc. 1996, 118, 50115019.

[37] S. A. d. Marothy, XYZ-viewer, 0.970: Stockholm, 2010. 
1

Entry for the Table of Contents (Please choose one layout)

Layout 1:

\section{FULL PAPER}

Macrocycles hold great promise in drug discovery, however their synthetic generation through macrocyclization is non-trivial. Here, the synthesis of two new cyclization precursors is described and the results of the ensuing cyclization is reported and evaluated. Molecular modeling is used to explain the observed results and provide guidance for further work in this field.

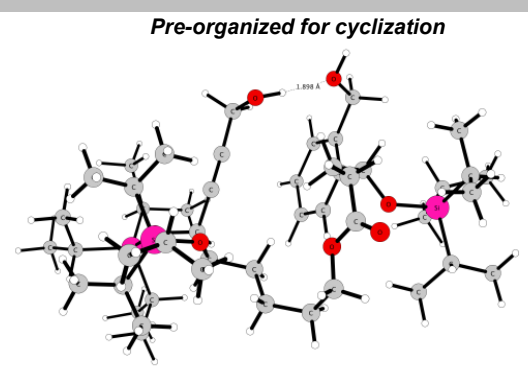

Macrocycles, Synthesis

Peter Hammershøj, ${ }^{[a],[b]}$ Klavs

Beldring, ${ }_{[a],[b]}$ Anders R. Nielsen, ${ }^{[a],[b]}$

Peter Fristrup, ${ }^{*[b]}$ Mads $\mathrm{H}$ Clausen. ${ }^{*[a],[b]}$

Page No. - Page No.

Observations on the Influence of

Precursor Conformations on

$1.5 \mathrm{~kJ} / \mathrm{mol}$ above global minimum 


\section{Click here to access/download Additional Material - Author
Fristrup_coverletter_revised_version.pdf Additional Material - Author
Fristrup_coverletter_revised_version.pdf}


Click here to access/download Supporting Information Fristrup_supporting information.pdf 
Click here to access/download Additional Material - Author suppinfo_xyz_structures.txt 